\title{
IMPLEMENTATION OF A DOSSIER-BASED SUBMISSION PROCESS IN A SENIOR DESIGN PROJECT COURSE
}

\author{
Hodgson, A J; Van der Loos, M; Fengler, M; Cramond, P; Winkelman P and Khorasany R \\ Department of Mechanical Engineering, University of British Columbia, Vancouver, BC, Canada \\ ahodgson@mech.ubc.ca
}

\section{INTRODUCTION}

At UBC, students taking the senior design project course associated with mechanical engineering have traditionally been required to submit a series of six reports at roughly monthly intervals. The primary purposes of these reports are (1) to give the students practice in the professional discipline of properly documenting their work, (2) communicating with the other stakeholders in the project, and (3) enabling their supervisors to assess the soundness of their design.

Historically, a number of students have reported feeling that these documentation requirements are onerous and slow their progress, and/or that the standard report sequence or the deadlines do not suit their project; in such cases, students may feel pressured to do a particular design task just because it is required for the report, rather than because they actually believed it would help move their project forward.

To mitigate these problems, we implemented a new dossier-based documentation scheme. Instead of formal reports, we asked the students to build a design dossier documenting key elements of their design. Students could adjust the weighting of different dossier elements to better reflect their specific design project and could choose (as part of their time management plan) when each element would be handed in. In addition, we simplified the formatting requirements to allow students to focus on presenting core information (e.g., substituting forms when possible). The purpose of this paper is to present our initial experience with using this new format.

\section{CURRENT REPORTING APPROACH}

Approximately ten years ago, the UBC Mechanical Engineering department changed its approach to running our capstone design course. Previously, our projects had been supervised by volunteer instructors, but this resulted in inequitable supervision loads and dramatically different expectations from project to project. By bringing all projects under a common administrative framework, we were able to have instructors and professors specifically assigned to this course (and receive teaching credit) and to harmonize our expectations and standards across instructors. In addition, we established the expectation that virtually all projects would be done on behalf of an external client and that a design-build-test-redesign cycle was to be a standard element.

Central to this change was a standardization of the reporting expectations. Students were required to submit approximately one significant report per month (six reports in all). These included: (1) a project proposal presenting the user assessment process, the project requirements and evaluation criteria, and the work plan, (2) a conceptual alternatives report presenting a function structure decomposition, a range of alternative solutions and the initial concept selection results, (3) a critical function prototype report presenting the results of early prototyping work aimed at proving the feasibility of the most promising approach(es) to the key function which needs to be implemented, (4) a technical analysis report focusing on optimizing the performance of the chosen concept, (5) a detailed design report, and (6) a final documentation package for the client presenting the results of the user evaluations, any verification or validation studies and any user documentation.

While our revised course was generally well-accepted by students and clients, students consistently expressed frustration with the reporting format, claiming that the uniform submission schedule across all projects failed to recognize critical differences in emphasis between projects and the formal nature of the reports consumed too much time and diverted them from making progress on what they saw as the real purpose of the project, which in their view was to build something. Although the instructors felt that, by and large, there was sufficient flexibility in what was requested of different teams to accommodate inter-team differences, the formal nature of the reports came to be perceived as a consistent irritant and impediment to students buying in to some of the broader goals of the course. This past year, therefore, we decided to adopt a different approach.

\section{DOSSIER-BASED REPORTING}

In September 2010, we introduced a new reporting process, which we referred to as Dossier-Based Submissions (DBS). The process was modeled on the design dossier which is frequently used in industries operating under the sorts of design control approaches normally implemented as part of ISO 9000-type quality control processes. In such industries, all design and development activities related to a particular product are documented by adding elements to a design file. Such design files contain numerous elements ranging from formal documents such as proposals to briefer elements such as memos reporting results of interviews or short test reports, along with routine documentation such as engineering change orders and weekly progress reports.

We therefore completely restructured our documentation requirements to emulate this approach. We told the students that they would be responsible for determining both what elements they would need to hand in and what schedule they follow in submitting their work. To assist them in managing their time, and to prevent them from handing in a mass of work at the last minute, we told them that they needed to present a work plan broken down by the number of person-hours that they planned to invest in the various phases of the project (a standard 4person team was expected to put in $8 \mathrm{~h} /$ week/person for 28 weeks, or 224 person-hours each, or 900 hours total per team). We asked them to organize the year into 12 phases, each lasting approximately two weeks ${ }^{1}$ (though this was variable), plus a $13^{\text {th }}$ 'Final Submission' phase. Within each phase, we asked them to break down their work to the point where they could identify both what design activities they planned to spend their time on and what documentation they intended to submit, and we encouraged them each week to ensure that they had time-management plans in place for roughly the next three phases (month and a half).

In the marking scheme, each team determined how much weight they planned to give to each phase. The weighting was based explicitly on how much time they planned to spend in each phase, and the volume of documentation was not tightly linked to the time spent. For example, during the prototype construction phase, the reports were relatively short, consisting mainly of photographs of key points in the building and assembly process. In contrast, a literature review and patent assessment process typically produced considerable documentation.

We encouraged the students to consider the need for each piece of documentation to be based on the need to communicate to their supervisors what they had been spending their time on and what the significance of what they'd found was for decision-making in their design project. That is, we emphasized that the documentation was not needed simply for the sake of documentation, but to help them have an intelligent and focused conversation with their supervisors. The briefest template we presented for most documentation was a simple memo with four sections: 1. Why? 2. How? 3. What? and 4. So What?

\section{DISCUSSION}

Although we don't have firm statistics to compare directly our previous formal reporting approach to our new dossier-based approach, our sense is that by and large students appreciate the new freedom and flexibility. Some didn't initially understand how much flexibility they had, and others failed to recognize the importance of producing standard forms of evidence of design activities they'd undertaken. In response to this, we have begun work on designing new rubrics to help students better understand our expectations. Anecdotally, we have observed that many students rapidly got into the habit of writing summary memos when they had client interviews or conducted tests, and we instructors generally felt more on top of our groups' progress than we have in previous years, so we intend to continue using this dossier approach.

These phases included, amongst others, user assessment, specifications, concept generation and selection, critical function prototyping, technical assessment, detailed design, prototype construction, and verification and validation. 


\section{REFERENCES}

1. Smith PA, Jones GA, Black LP. J Materials 2001;34:545-9.

2. McMaster DS, Robson MA. Science 1992;17:66-73.

3. Brown AL. Engineering 1981;6:93-7.

4. Pope PM et al.. ABC $22^{\text {nd }}$ Meeting, 2006. 